\title{
A IMPORTÂNCIA HISTÓRICO-SOCIAL DOS REGISTROS PAROQUIAIS NO BRASIL SETECENTISTA
}

\author{
Valdeci Silva Izabel Junior ${ }^{1}$
}

Resumo: O principal interesse deste trabalho é explorar algumas potencialidades que podem ser extraídas dos documentos paroquiais setecentistas, através das argumentações e propostas expostas, considerando sua importância, não só, como mecanismos de controle da Igreja e da Coroa, mas, também, como suportes de informações sobre a sociedade civil de suma importância no campo de pesquisa da demografia histórica. Assim como promover um estudo compartilhado sobre as possibilidades de utilização do conteúdo dessas fontes primárias para a compreensão das relações e formação das redes familiares que se consolidavam a partir da recepção dos sacramentos do batismo e do matrimônio.

Palavras-Chave: Registros Paroquiais; Concílio de Trento; Relações Familiares.

\footnotetext{
${ }^{1}$ Graduando em História pela Universidade Federal Fluminense, Polo Universitário de Campos dos Goytacazes-RJ, e bolsista de Iniciação Científica da FAPERJ, vinculado ao Laboratório de Pesquisa e Documentação em História Econômica e Social (LAPEDHE), sob orientação do Prof. Dr. Márcio de Sousa Soares. valdesij@id.uff.br
} 
Abstract: The main interest of this paper is to explore some potentialities that can be extracted from eighteenth-century parish documents, through the argumentations and proposals exposed, considering its importance, not only, as mechanisms of control from the Church and the Crown, but, also, as information support about the civil society of paramount importance in the historical demography research field. As to promote a shared study about the possibilities of the use of this primary sources content to the understanding of the relations and arrangement of family networks that were consolidating from the reception of the sacraments of baptism and matrimony.

Key-words: Parish Registers; Council of Trent; Family Relations

Os assentos paroquiais de batizados, casamentos e óbitos formam um acervo importantíssimo para conhecermos o modus vivendi da sociedade brasileira no período colonial e imperial. São fontes que contribuem na compreensão de nossa história passada.

Sheila de Castro Faria, em seu livro: A colônia em movimento: fortuna e família no cotidiano colonial, na observação "dos múltiplos relatos de pessoas com suas maneiras de viver, sofrer, trabalhar e morrer [na] capitania do Paraíba do Sul - [nos] Campos dos Goitacases" afirma que: 
Os registros paroquias, bem mais enxutos, em termos de informações, e mais padronizadas, também podem ser considerados como fundamentais para um esboço da vida cotidiana familiar dos cativos. (FARIA, 1998, p. 313).

Pelo fato de que prevalecia uma cosmovisão religiosa à época setecentista, os principais momentos da vida, inclusive os sociais, eram marcados pela assistência da Igreja: no batismo, no casamento e na morte e foram assentados nas "atas" paroquiais, assim como na feitura de testamentos, incentivados pelos párocos.

Ao fazer uma análise sobre os "eventos vitais na reconstituição da história", Maria Silvia Bassanezi ressaltou que os registros de batizado e matrimônio eram feitos em algumas dioceses europeias no século XVI, seguindo as decisões do Sagrado Concílio de Trento (15451563), que determinavam a obrigatoriedade e padronização dos registros paroquiais (BASSANEZI, 2011, p.146). A ação da Igreja Católica, neste momento, em que se pretendia conquistar novos adeptos e registrar os fiéis, sob o impulso Tridentino, formou a mentalidade e a cultura da América portuguesa.

Anos antes do Concílio, pelas Constituições de Lisboa (1536) já eram feitos os registros, após sua realização, essas normas foram estendidas às áreas de colonização portuguesa pelas Constituições de Coimbra (1591). O primeiro bispado erigido no Brasil foi em 1551, 
porém, somente em 1707 que definiram normas eclesiásticas, que foram estabelecidas nas Constituições Primeiras do Arcebispado da Bahia, na linha tridentina (BASSANEZI, 2011, p.143-147).

Para penetrarmos na realidade sociocultural desse período, nas palavras de Martha Hameister, que pesquisou intensivamente os aspectos e as estratégias de formação familiar na Vila do Rio Grande (1738-1763), é preciso compreender que o Brasil nasceu católico e que publicamente a população professava o catolicismo:

[...] E estamos a falar de uma sociedade erigida sob a égide do catolicismo romano - [...]. Com isso, os sacramentos da Igreja, e em especial o batismo de crianças e adultos pagãos, eram bastante procurado, pois, segundo as Constituições Primeiras do Arcebispado da Bahia, "o batismo é o primeiro de todos os Sacramentos e porta por onde se entra na Igreja Católica" (Da Vide, 1707, Livro I, Título X §33). (HAMESITER, 2006, p.9394, grifo nosso)

Era importantíssima a participação nos rituais católicos, principalmente, do Batismo, onde, o pagão entrava na vida da Igreja tendo o ministro do batismo pronunciado a fórmula: Ego te baptizo in nomine Patris et Filii, et Spiritus Sancti. ${ }^{2}$ De acordo com a Igreja, após a recepção do primeiro sacramento, o batizando torna-se participante

${ }^{2}$ Eu te batizo em nome do Pai e do Filho e do Espírito Santo. 
dos benefícios da crença religiosa e pode se salvar eternamente (VIDE, 1853, p. 13).

Sendo de caráter obrigatório e padronizado, na análise de Bassanezi, os registros paroquiais possuíam representatividade e eram universais, seriais e cronológicos, forjando uma documentação individual e coletiva de grande importância para a história social (BASSANEZI, 2001, 143-146).

Aqueles que não aderiram a Fé católica ficaram de fora de tais assentos, no entanto, os registros de batismo, "para toda a Colônia, são os mais "democráticos" - no sentido de cobrirem uma mais variada gama da população e, por consequência, um número bem maior de pessoas do que outras fontes documentais" (HAMEISTER, 2006, p.188).

A preocupação com a salvação da alma, com a "boa morte" era intrínseca a essa sociedade. Por isso é indispensável, para eficácia da pesquisa, perscrutar o papel sócio-histórico e cultural da religião e seu impacto no quotidiano colonial e imperial brasileiro.

Um instrumento de controle da população católica, num momento em que não existia outro registro, além do paroquial, foi também utilizado com fins jurídicos. Em muitos lugares, tal gerência da Igreja, perdurou por décadas no "pós-império". 
Como se organizava com base no padroado régio, o Estado português tinha função de organizar e prover as necessidades da Igreja. ${ }^{3}$ A expansão colonial foi fundamental para que se propagasse a religião católica e para que esses métodos organizacionais fossem aplicados.

Dessa forma, o conteúdo dos registros paroquiais também poderia ser utilizado para finalidades civis (comprovação de origem, paternidade e estado matrimonial), já que o registro civil surgiu apenas no século XIX, se estabelecendo, de fato, na República. Por sinal, o surgimento do registro civil, em 1874, não foi bem visto, não somente pela Igreja, como também pela população, devido à distância entre a residência de muitas pessoas e a localização do cartório para a realização do registro:

Os próprios órgãos governamentais, muitas vezes, atribuíam mais confiança ao registro religioso de batismo, casamento ou óbito. Este atingia mais pessoas $e$ localidades devido à infraestrutura montada pela Igreja no decorrer da Colônia e Império. Párocos e missionários periodicamente visitavam o território das localidades sob

\footnotetext{
3 "Padroado - Regime cuja origem remonta a Idade Média, pelo qual a Igreja instituía um indivíduo ou instituição como padroeiro de certo território, a fim de que ali fosse promovida a manutenção e propagação da fé cristã. Em troca o padroeiro recebia privilégios, como a coleta de dízimos e a prerrogativa de indicar religiosos para o exercício das funções eclesiásticas" (VAINFAS, 2000, p. 466-467). As coroas portuguesa e espanhola tinham esse beneplácito, em relação à religião. O padroado permaneceu no Brasil até a proclamação da República, em 1889.
} 
sua responsabilidade para administrar os sacramentos. (BASSANEZI, 2011, p. 156 grifos nossos)

Antes da separação entre a Igreja e Estado os registros paroquiais eram os únicos documentos disponíveis sobre os principais "eventos vitais". A legislação da Igreja era criteriosa, o grande problema, detectado pelos visitadores, era a falta de zelo de alguns párocos no cumprimento exato daquilo que estava estabelecido nas Constituições Primeiras e pelas Pastorais, no entanto, as fontes continuam tendo sua validade:

As paróquias estavam também sujeitas a visitas pastorais ou diocesanas que avaliavam o desempenho dos próprios párocos, pelo menos uma vez ao ano, contribuindo desse fora para a maior abrangência dos registros da Igreja. (BASSANEZI, 2011, p. 156 grifos nossos)

Os padres que negligenciasse a administração dos sacramentos e seu registro nos assentos paroquiais deveriam ser penalizados por tal culpa, diante de Deus e dos homens, como determinava as Constituições Primeiras do Arcebispado da Bahia ao afirmar que se "fazendo o contrário [do que foi ordenado], serão castigados (...) com as penas de Direito, e com as mais que nos parecer, segundo a qualidade, e circunstancias das culpas.” (VIDE, 1853, p. 11). 
A responsabilidade de fazer esses registros ficava por conta dos respectivos párocos, dependendo da freguesia e da demanda de assistência aos sacramentos, eles teriam que contar com uma boa memória para anotar as informações concedidas pelos pais ou padrinhos e depois passá-las para os assentos paroquiais.

Entretanto, vemos através das redes de parentescos que podemos "tecer" em novas pesquisas com essas fontes, que, mesmo com falhas na lembrança do Cura, ainda assim, elas são ricas de sinais e detalhes do quotidiano colonial e imperial.

Utilizadas incialmente pelos genealogistas, o uso dos registros paroquiais como fonte de pesquisa se intensificou a partir da Segunda Grande Guerra com o advento da demografia histórica (BURGUIÈRE, 1995, p.59). A partir de então, surge o interesse de "desbravar" esse mar que limitava a historiografia à generalização, como foi o caso dos estudos sobre a escravidão na América Portuguesa e no Brasil Império, revelando novas abordagens da relação senhor-escravo, assim como sobre a religiosidade (GUEDES, 2008; RODRIGUES, 1997). Questionamentos que, outrora foram abafados ou desmerecidos, retornam ao cenário historiográfico com novos enfoques e dimensões.

Os registros paroquiais são como luminárias, que nos possibilitam enxergar detalhes ainda obscuros em nossa historiografia, 
dedicada ao período setecentista, seja pela miopia causada pelas ideologias ou, até mesmo e, principalmente, por uma visão cristalizada do período.

Não basta ter um enorme quantitativo de fontes se não sabemos utilizá-las como ferramentas eficientes para nossa pesquisa. É necessário saber interrogá-las e não influir com preconceitos para obter resultados que legitimem nossa opinião ou crença, para que possamos nos aproximar, o quanto possível, da realidade pesquisada.

Por isso é tão importante o cruzamento das fontes paroquiais, com as listas nominativas, testamentos, inventários, para relacionarmos as linhas onomásticas e chegarmos a uma observação em escala pormenorizada.

No passado, podiam-se acusar os historiadores de querer conhecer somente as "gestas dos reis". Hoje, é claro, não é mais assim. Cada vez mais se interessam pelo que seus predecessores haviam ocultado, deixado de lado ou simplesmente ignorado. (GINZBURG, 2008, p.11)

Carlo Ginzburg traz essa perspectiva de uma história que parte do micro para compreender o macro. Possibilidades ora ocultadas, desconhecidas ou simplesmente desconsideradas são, agora, valorizadas. A demografia histórica e a microanálise utilizando-se das 
Revista Vernáculo, $n^{\circ} 29,1^{\circ}$ sem/2012

fontes paroquiais, nesse recorte setecentista, nos ajudam a remontar as relações de parentesco e as redes familiares que se constituíam ao redor das freguesias.

Fazendo o trabalho paleográfico (leitura e transcrição) da documentação, separei dois casos, que me chamaram bastante atenção, para ilustrar essas especificidades que podemos encontrar nos registros paroquiais.

São os assentos de dois batizados da Freguesia de São Salvador dos Campos dos Goitacases, um do ano de 1769 e outro de 1770, que trazem aspectos singulares e instigantes:

Aos quatro dias do mês de Novembro do anno de mil e sette centos e settenta, nesta Matriz de São Salvador, baptizei e pus os santos óleos a Crispim, exposto em casa de Manoel Menezes, forão padrinhos Pedro, escravo de João da Silva Rangel e Rita de Souza, todos desta Freguesia do que para constar fiz este assento que assignei. José Pereira de Almeida. Coadjutor. (ACMCG Livro de Batizado de Livres n. 1, 1762-1777)

Neste primeiro caso, ocorreu que o batizando é um exposto. As Constituições Primeiras determinavam que no registro, deveria conter o nome dos pais, entretanto, no caso das crianças que foram enjeitadas, portanto, não haveria possibilidade de nomeá-los, pois, ao serem 
enjeitados e expostos em casa de alguém, não havia a possibilidade de identificá-los.

Na intepretação do Vocabulario Portuguez e Latino do Pe. Raphael Bluteau, uma criança enjeitada é aquela "desamparada de seus pais, exposta no átrio de uma Igreja, num convento ou em casa particular" (BLUTEAU, 1798, p.116).

Sobre o caso de Crispim $^{4}$, somente tenho indagações que podem nortear a pesquisa ou, ao menos, promover seu início. Através dos diversos estudos sobre compadrio, poderei encaminhá-la, relacionando as fontes e "desvendando", o quanto possível, esses relacionamentos.

Entretanto, algumas perguntas são inevitáveis e merecem um estudo mais sistemático e o cruzamento de fontes para compreender as peculiaridades deste caso: Quem é Manoel de Menezes, que recebeu em sua casa o enjeitado? Qual a relação entre o dito Manoel e Pedro, padrinho que é um escravo e/ou com seu senhor João da Silva Rangel?

Ao longo das indagações sobre os casos, pesquisei várias análises sobre os expostos, compadrios de livres, por pardos livres ou escravos e a formação das redes familiares através do apadrinhamento.

\footnotetext{
${ }^{4}$ Os comentários sobre o caso não são uma análise sistemática, mas, sim, hipotética das possibilidades da utilização das fontes paroquiais, na pesquisa.
} 
O ritmo das emergentes possibilidades de exploração dessa fonte primária, os registros paroquiais, é concomitante com as leituras historiográficas que trazem interpretações mais sofisticadas para além do senso comum.

Para que a investigação não seja anacrônica ou mesmo carregada de pressupostos contemporâneos é fundamental distinguir a ótica da sociedade hodierna, que preza a secularização, da setecentista, que, era não somente marcada, como concebida pela religiosidade.

Por isso, de acordo com a doutrina católica, o batismo é algo inegável, pois de forma alguma um inocente poderia pagar pelas mazelas de seus genitores. Portanto, sendo a criança legítima, natural ou exposta, ela deveria receber o batismo para salvação de sua alma e remissão do pecado original.

O padre jesuíta Alexandre de Gusmão (1685) é categórico na defesa do batismo desses inocentes, defendendo que se devia salvaguardar antes de todos os outros benefícios o direito a "vida espiritual", alcançada no batismo e, se o amor fosse ordenado, antes de todas as preocupações, a mais grave é a de lucrar a "vida eterna". 5 (ARAUJO; TOLEDO, 2008, p.145)

\footnotetext{
${ }^{5}$ A perspectiva conjuntural é da América Portuguesa nos séculos XVII e XVIII e deve ser compreendida dentro dessa cosmovisão.
} 
Isto posto, essa documentação abre novas oportunidades de esquadrinhamento do tema. $\mathrm{O}$ ato de expor uma criança poderia significar uma tentativa de promover a estabilidade da estrutura familiar, mantendo, ao menos ocultamente, as transgressões das leis morais e religiosas.

Sheila Faria sustenta que "o abandono de crianças foi majoritariamente um fenômeno urbano, mesmo no período colonial brasileiro" e, nesses casos, é interessante ressaltar que os pais nem sempre eram totalmente desconhecidos (FARIA, 1998, p. 69).

Na região de Campos dos Goytacazes, como afirma Faria, a exposição de crianças ocorria quase sempre em casas particulares - o que não era feito de forma aleatória, visto que os receptores tinham características determinantes para essa escolha - perdurou até o fim do século XVIII, com a criação da Santa Casa de Misericórdia e criação da roda dos expostos pela Irmandade de Nossa Senhora Mãe dos Homens (FARIA, 1998, p. 68-74). ${ }^{6}$

\footnotetext{
6 "O nome roda se refere a um artefato de madeira fixado ao muro ou janela do hospital, no qual era depositada a criança, sendo que ao girar o artefato a criança era conduzida para dentro das dependências do mesmo, sem que a identidade de quem ali colocasse o bebê fosse revelada. As primeiras iniciativas de atendimento à criança abandonada no Brasil se deram, seguindo a tradição portuguesa, instalando-se a roda dos expostos nas Santas Casas de Misericórdia. Em princípio três: Salvador (1726), Rio de Janeiro (1738), Recife (1789) e ainda em São Paulo (1825), já no início do
} 
As famílias que expunham seus filhos geralmente habitavam núcleos populacionais mais amplos, pois, se fossem moradores de pequenas zonas rurais facilmente se conheceria o pai e/ou a mãe que a enjeitou; o que não significa dizer que em todos os casos esses eram desconhecidos.

De forma genérica é impossível analisar a exposição, pois, ela "representava a própria manutenção da estabilidade, ou melhor, dizendo, da moralidade familiar" (FARIA, 1998, P.71). Isso significaria que tanto uma família abastada, para preservar o nome da família, quanto para uma mulher solteira, para impedir humilhações públicas.

A possibilidade de que casais desafortunados, expusessem seus filhos era menor do que a dos mais ricos, pois, caso sobrevivesse, essa criança posteriormente teria a capacidade de ajudar no trabalho familiar.

Enjeitar uma criança, sendo de forma provisória, como poderia acontecer com famílias numerosas ou definitivamente, o intuito era manter estáveis as "estruturas familiares" e afastar uma gravidez indesejada.

império. Outras rodas menores foram surgindo em outras cidades após este período." Disponível em:

http://www.histedbr.fae.unicamp.br/navegando/glossario/verb_c_roda_dos_expostos.h tm> Acessado em 2 de Out. de 2013. 
Depois de percebermos diversas probabilidades que poderiam ter resultado na exposição de Crispim, que poderemos averiguar posteriormente através da pesquisa, nos deparamos com um episódio de apadrinhamento vertical, aparentemente, desvantajoso: um escravo padrinho de um livre.

O compadrio era a firmação de um parentesco espiritual, de tal forma consolidado, a ponto de que quem o contraísse tinha restrições para se unirem em matrimônio:

[...]Dito os padrinhos, como ficão sendo fiadores para com Deos pela perseverança do baptizado na Fé, e como por serem seus pais espirituaes, tem obrigação de lhes ensinar a Doutrina Christã e bons costumes. Tambem lhes declare o parentesco espiritual, que contrahirão, do qual nasce impedimento, que não só impede, mas dirime o Matrimonio: o qual parentesco conforme a disposição do Sagrado Concilio Tridentino. (VIDE, 1853, p. 26-27)

Ao se tornar "fiador para com Deus", o padrinho tem a obrigação de zelar pela alma de seu afilhado. Tratando-se de livres apadrinhando escravos, constitui uma relação vertical, firmando parentesco com uma pessoa de posição social superior a do batizando e sua família, o que poderia possibilitar uma troca de favores, pois o escravo não era um agente passivo nesses tratos. 
As relações de compadrio vertical podem ser compreendidas pela busca de proteção e segurança, que extrapolava o caráter religioso. Não se excluindo, assim, o apadrinhamento horizontal que estabelecia vínculos de colaboração bilateral entre "iguais".

Tendo como base as relações pessoais, nesta sociedade era importante fazer novos e fortalecer os antigos vínculos. Com respaldo da religião, essa ligação de "parentesco espiritual" favorecia essas uniões. Seja com um superior, criando possibilidades de reconhecimento social ou com um de mesmo nível, o que garantirá auxílios recíprocos nas devidas proporções de suas desigualdades.

Estes elos que se formavam nas relações de compadrio e consanguíneas corroboravam a noção tomista da sociedade como um corpo, constituído de partes desiguais, hierarquicamente ordenadas, sendo isso, um ordenamento social considerado justo, de acordo com uma noção de direito que reservava a cada um, o que era seu. (AQUINO, 1980, p.2499)

O "laço espiritual", segundo Schwartz, tratando-se do batizado de um inocente, criança até os sete anos, era estabelecido entre "os padrinhos e os pais", sendo adulto "entre os padrinhos e o cristão que acabara de ganhar um nome e passar pela iniciação". (SCHWARTZ, 2001, p. 265). 
A relação do apadrinhamento, não se dava somente no campo religioso, pois se tornava, numa ótica mais ampla e dinâmica, um instrumento que garantia aliados no intuito de adquirir benesses, seja espiritual ou temporal.

Adequando as peculiaridades locais e temporais, para não incorrermos no "pecado gravíssimo" da generalização historiográfica, podemos nos valer do estudo de Schwartz, sobre o Recôncavo Baiano, onde percebeu os escravos não eram apadrinhados pelos seus senhores, mesmo tendo, nos casos estudados, $70 \%$ com padrinhos livres (SCHWARTZ, 1988, p. 330).

É inegável a prevenção na formação desse parentesco familiar entre senhores e escravos, pois havia uma dicotomia entre a libertação causada pelo batismo e o sistema escravocrata. Por isso, tendo padrinhos ou compadres livres, os mesmos poderiam atuar como intermediários nas situações conflituosas entre escravo e senhor (SCHWARTZ, 1988, p.330-334); e, em relação aos cativos que se apadrinhavam entre si, fortaleciam e/ou afirmavam laços de amizade e aproximação de familiares consanguíneos.

Renato Pinto Venâncio, estudando as relações de apadrinhamento em Vila Rica, do fim do século XVIII, traz aspectos da verticalidade desse processo, onde forros apadrinham escravos e se 
Revista Vernáculo, $n^{\circ} 29,1^{\circ}$ sem/2012

tornavam poderosos "mediadores da comunidade de libertos $e$ escravos" (VENÂNCIO, 2006, p. 273), potencializando as intermediações sociais.

A historiografia brasileira sobre compadrio, usando dos recursos das fontes paroquiais, percebeu que “[...] os escravos eram apadrinhados tanto por escravos como por livres; os nascidos livres eram quase sempre apadrinhados por livres" (GUDEMAN; SCHWARTZ, 1988, p. 46).

Escravos ou forros apadrinhando escravos, de acordo com Maria de Fátima R. das Neves, que se deteve na análise sobre São Paulo (1801-1810), era uma forma de vinculação afirmada, ou seja, "fazendo nossas as palavras de Stuart Schwartz, o compadrio entre escravos era horizontal, ou, na maioria das vezes vertical para cima”, o que significaria dizer que, "o contexto escravista fornecia a direcionalidade social na escolha dos padrinhos de batismo" (NEVES, 1990, p. 243).

Que esses laços "podiam ser usados para reforçar laços de parentesco já existentes, ou solidificar relações com pessoas de classe social semelhante, ou estabelecer laços verticais entre indivíduos socialmente desiguais" (SCHWARTZ, 2001, p. 266), tem-se tornado evidente, nesta nossa análise, no entanto, fica o questionamento, se essa relação vertical seria somente "para cima". 
Revista Vernáculo, $n^{\circ} 29,1^{\circ}$ sem/2012

Silvia Brügger traz essa perspectiva (a mais provável), de que os apadrinhamentos, entre os desiguais, era uma formalização de mecanismos de proteção prestígio social e entre os iguais buscavam favorecimentos para melhorar o quotidiano (BRÜGGER, 2007, p. 315$347)$.

Analisando casos de exposição da Freguesia de São Salvador nos Campos dos Goitacases, no período de 1754 a 1796, Faria afirma, contundentemente, que enjeitar crianças foi "uma das formas socialmente aceitas para os que se viam impossibilitados de reconhecer ou criar filhos". Havia outras, desde o aborto ao infanticídio, ou menos grave que "seria atribuir o filho a outra pessoa" (FARIA, 1998, p.8586).

O caso de Crispim, da dita Freguesia de São Salvador, estava inserido em alguma dessas causas. As possibilidades são diversas, principalmente, pelo fato de que estes que recebiam em suas casas, por via de um mapeamento agrário, foram identificados como pessoas de boa condição de vida.

Esse vínculo familiar, "para baixo", que é era formado com um desigual, aparentemente, mesmo sendo uma exceção, nos faz questionar sobre as relações livre-escravo-livre no final do setecentos e a formação 
de grupos de parentesco, onde os escravos e libertos conseguiriam forças para sua organização e legitimação social.

Outro assento paroquial que merece atenção é o de Antônio, batizado no final da década de sessenta, no período setecentista:

Aos dezoito dias do mês de Agosto do anno de mil e sette centos e secenta e nove, nesta Matriz de São Salvador, baptizei e pus os santos óleos a Antonio, filho de Anna escrava do Reverendo Padre Angelo Pessanha, forão padrinhos Antonio Jose Palhares, por procuração do Reverendo Vigário da Aldêa de Santo Antônio de Guarulhos Antonio Ramos de Macedo e Joanna Antonia, filha do defunto Ignacio Velhoso, foi baptizado por forro e por liberto por ser me apresentar essa declaração em escritta feita e asignada pelo mesmo dito Reverendo Padre Angelo Pessanha em que se assignou. Cujo teor é o seguinte// Por este por mim feito e assignado dou todo o pleno consentimento para que o Reverendo Padre da Freguesia de São Salvador, destes Campos possa cumpridas as circunstâncias da lei e estilo baptizar por forro uma criança, filho de uma escrava minha por nome Ana Santa Cruz. Oito de Agosto de mil e sette centos e secenta e nove, padre Angelo Pessanha// Oito de agosto de 1769 padre Angelo Pessanha//E não se continha mais na dita declaração, do que para constar fiz este termo na presença do mesmo Antônio José; Caetano Pinto Duarte e Antonio Furtado de Mendonça que todos comigo juntamente assinaram e eu assinei era ut supra. José Pereira de Almeida. Coadjutor. (ACMCG - Livro de Batizado de Livres n. 1, 1762-1777) 
Este extensivo registro de batismo do ex-escravo Antônio, forro na pia, ou seja, que recebeu sua liberdade no momento do batismo, nos força a querer analisar a projeção social do compadrio e a dinâmica dessas relações, vendo o escravo também como um agente nesse processo.

Nos passos da pesquisa empreendia por Márcio de S. Soares sobre a "dádiva" e "as motivações" das concessões das alforrias, nos Campos dos Goitacases, no período de 1750-1830, o autor reconhece que a maioria "das alforrias de crianças ilegítimas, era, sem dúvida alguma, uma tentativa quase sempre silenciosa de corrigir", atos irresponsáveis, na concepção moral daquela sociedade, perante os homens e, principalmente, para não sofrer as penas do purgatório, segundo a doutrina católica (SOARES, 2009, p.84).

Desta forma, para um senhor de escravo tornar um inocente forro era uma oportunidade para reduzir suas penas no purgatório, fosse a criança sua filha ou não visto que a alforria de inocentes no ato do batismo também era vista como um ato de caridade feito "pelo amor de Deus". O Batismo é o sacramento em que a criança passa "da culpa a graça" (VIDE, 1853, p.14), adquirindo neste caso, um sentido duplo "de purificação: para o nascituro tratava-se de supressão do pecado original, ao passo que para o pai" era o "início de sua remissão" 
(SOARES, 2007, p.392-393). Ao fazer essas afirmações Soares não generaliza as alforrias de pias, considerando todas elas resultantes de "tratos ilícitos".

Para Soares, todas as alforrias concedidas "eram entendidas como um favor e a liberdade dele resultante como uma doação" (SOARES, 2009, p.178). O que contraria certas análises, principalmente mais marxistas que as caracterizam como um jogo de interesses mercantis e econômicos, portanto, elas não poderiam se reduzir a "um ato comercial", pois, "a negociação da liberdade e seus desdobramentos tinha natureza de implicações políticas" (SOARES, 2007, p.389).

Essa relação, fortemente desigual, era de favorecimentos mútuos, enquanto concedia ao batizando sua alforria na pia de batismo, ali também, buscava libertar-se dos tormentos de sua consciência culpada e, ao mesmo tempo, selava uma relação de dependência entre os pais ou a mãe da criança alforriada, em virtude da obrigação moral de gratidão que se estabelecia entre os libertos e seus ex-senhores que se transformavam em patronos, isto é, protetores (SOARES, 2009; GUEDES, 2008).

Embora fossem pontuais e seletivas, não sendo tão comuns, essas alforrias demonstravam a força e o "papel decisivo" que "o 
imaginário religioso do catolicismo e a moral" exerciam nessas libertações, em alguns casos acompanhadas de doação de bens, provendo o necessário, para que os libertos pudessem seguir a vida (SOARES, 2007, p.415-416).

Se a motivação do Reverendo Padre Angelo Pessanha foi afetiva, pecuniária ou tentativa de remissão de suas penas diante de Deus no post-mortem, não podemos influir, simplesmente.

Por meio do levantamento de novas fontes e o cruzamento delas, analisando as redes consanguíneas e afetivas, chegaremos ao conhecimento, o quanto possível, mais próximo da realidade histórica.

Apresentei, nestes dois casos que me intrigaram e acabaram provendo as fontes necessárias na construção deste artigo, um programa e metodologias as quais, utilizarei no desenvolvimento de minha pesquisa e o valor, incomensurável, dos registros paroquiais que com ou outras fontes nos ajudam a reconstituir não somente o modo de vida, como também a mentalidade que regia esse modo de viver.

Temos muito que explorar dessa "galinha dos ovos de ouro" que são os registros paroquias, com uma metodologia cada vez mais apurada e um relacionamento mais intenso e cuidadoso com nossas fontes. 
Revista Vernáculo, $n^{o} 29,1^{o}$ sem/2012

"Muito, ainda, é necessário ser feito para que possamos recuperar não só as demais atitudes de escravos em relação a estes aspectos de suas vidas como também as da população livrelliberta" (FARIA, 1998, p.350). É dessa forma que vejo a imensidão de questionamentos que podemos fazer às fontes, que utilizarei, como instrumento eficiente em nosso ofício de pesquisa historiográfica.

\section{Referências}

Fontes Primárias:

ARQUIVO DA DIOCESE DE CAMPOS DOS GOYTACAZES . Livro $3^{\circ}$ de Batismo de Livres. 1762-1777.

BLUTEAU, D. Raphael. Vocabulario Portuguez e latino (Volume 03:

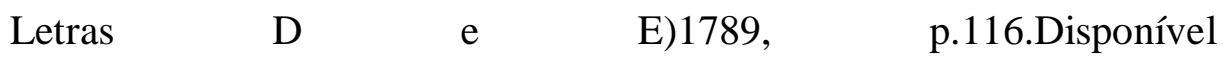
em: $<$ http://www.brasiliana.usp.br/bbd/handle/1918/00299403\#page/441/mode/1up> Acessado em 01 Out. 2013.

VAINFAS, R. [org.]. Dicionário do Brasil Colonial (1500-1808). Rio de Janeiro: Objetiva, 2000, p.466-467.

VIDE, S. M. (1720). Constituições primeiras do arcebispado da Bahia, feitas, e ordenadas pelo ilustríssimo e reverendíssimo senhor Sebastião 
Revista Vernáculo, $n^{\circ} 29,1^{\circ}$ sem/2012

Monteiro da Vide (...). Coimbra: Real Colégio das Artes da Companhia de Jesus.

Bibliografia de Consulta:

AQUINO, Tomás. Suma teológica. Trad. De Alexandre Corrêa, organização de Rovílio Costa e Luis A. de Boni. 2a. ed. Porto Alegre: Escola Superior de Teologia São Lourenço de Brindes, Sulina Editora; Caxias do Sul, Universidade de Caxias do Sul, 1980, vol. V.

ARAÚJO, Vanessa F. de; TOLEDO, Alencar Arnaut de; Sobre a Concepção de Infância do Padre Alexandre de Gusmão (1629-1724). In: UEPG Ci. Hum., Ci. Soc. Apl., Ling., Letras e Artes. Ponta Grossa, 16 (1) $141-152$, jun. 2008

BASSANEZI, M. S. Os eventos vitais na reconstituição da história. In PINSKY, C. B.;LUCA, T. R. de (orgs.) O Historiador e suas fontes. São Paulo: Contexto, 2009, p. 141-172.

BOURDIEU, Pierre. A economia das trocas simbólicas. Perspectiva, 2005.

BRÜGGER, Silvia Maria Jardim. Escolhas de padrinhos e relações de poder: uma análise do compadrio em São João Del Rei (1736-1850). In: CARVALHO, José Murilo de (org.). Nação e cidadania no Império: novos horizontes. Rio de Janeiro: Civilização Brasileira, 2007, p. 315347. 
Revista Vernáculo, $n^{\circ} 29,1^{\circ}$ sem/2012

BURGUIÈRE, A. A demografia. In: LE GOFF, J.; NORA, P. História: novas abordagens. Rio de Janeiro: Francisco Alves, 1995.

FARIA, S. de C. História da família e demografia histórica. In: FLAMARION, C. C.;VAINFAS, R. Domínios da história: ensaios de teoria e metodologia. Rio de Janeiro: Campus, 1997.

FARIA, Sheila de Castro. A Colônia em movimento: Fortuna e Família no Cotidiano Colonial. Rio de Janeiro: Nova Fronteira., 1998.

FLORENTINO, M.; GÓES, J. R. A paz das senzalas: famílias escravas e tráfico atlântico (Rio de Janeiro, 1790-1850). Rio de Janeiro: Civilização Brasileira, 1997.

GINZBURG, Carlo. O queijo e os vermes: O cotidiano e as ideias de um moleiro perseguido pela Inquisição. São Paulo: Companhia das Letras, 2008.

GUEDES, R. (2008). Egressos do cativeiro: trabalho, família, aliança e mobilidade social (Porto Feliz, SP, c.1798 - c.1850). Rio de Janeiro: MAUAD/FAPERJ.

GUSMÃO, Alexandre de. Arte de criar bem os filhos na idade da puerícia. Lisboa: Typ. do Colégio, 1685.

HAMEISTER, Martha Daisson. Para dar calor à nova povoação: estudo sobre estratégias sociais e familiares a partir de registros batismais da Vila do Rio Grande (1738-1763). Tese de Doutorado - 
Revista Vernáculo, $n^{\circ} 29,1^{\circ}$ sem/2012

Programa de Pós Graduação em História Social, Universidade Federal do rio de Janeiro, 2006.

LAGO, Rafaela D. Entre santas e homens: o compadrio na Freguesia de Vitória (1850-1871). Disponível em: <http://www.encontro2012.mg.anpuh.org/resources/anais/24/13407595 91_ARQUIVO_RafaelaDomingosLago.pdf>. Acessado em 03 de Out. de 2013.

MARCÍLIO, Maria L. Os registros paroquiais e a História do Brasil. In. Varia História, n.31, jan.2004, p.14.

NEVES, M. de F. R. das, Ampliando a família escrava: compadrio de escravos em São Paulo no século XIX. In: NADALINS, S. O., MARCÍlIO, M. . (orgs.), História população: estudos sobre a América Latina, São Paulo: ABEP, IUSSP, CELADE, Fundação SEADE, 1990, p. 243.

SCHWARTZ, Stuart B. Escravos, roceiros e rebeldes. Bauru, SP: EDUSC, 2001.

. , Stuart B. Segredos internos: engenhos e escravos na sociedade Colonial: 1550-1835. São Paulo: Companhia das Letras, 1988.

SOARES, Márcio de Sousa. A remissão do cativeiro: a dádiva da alforria e o governo dos escravos nos Campos de Goitacases, c.1750c.1830. Rio de Janeiro: Apicuri, 2009. 
Revista Vernáculo, $n^{\circ} 29,1^{\circ}$ sem/2012

., Márcio de Souza. AD Pias Causas: as motivações religiosas na concessão das alforrias (Campos dos Goitacases, 1750-1830). Cadernos de Ciências Humanas - Especiaria. v.10, n.18, jul.-dez. 2007, p.389-425.

VENÂNCIO, Renato Pinto; SOUSA, Maria José Ferro de; PEREIRA, Maria Teresa Gonçalves. O compadre governador: redes de compadrio em Vila Rica de fins do século XVIII. In: Revista brasileira de História. São Paulo: ANPUH, vol. 26, n 52, jul.-dez., 2006. p.273-294. 